\title{
Primary Swellings of Thyroid with the Cytodiagnosis of Invasive Squamous Cell Cancer - A Case Report
}

\author{
Anil Agrawal ${ }^{1}$, Anup Kedia 2 , Aanchal Manchanda 3 , Arvind Bhake ${ }^{4}$, Sunita Vagha ${ }^{5}$ \\ 1,2,3,4,5 Department of Pathology, Jawaharlal Nehru Medical College, Datta Meghe Institute of Medical Sciences \\ (Deemed to Be University), Sawangi Meghe, Wardha, Maharashtra, India.
}

\section{INTRODUCTION}

Metastasis to thyroid is a rare entity. Such patients present to the clinicians as a thyroidal swelling with undisturbed thyroid function tests. Although thyroid is known for its high vascularity, the presence of metastasis to the thyroid is still a rarity. ${ }^{1}$ The primaries for metastasis in the thyroid gland comes from breast, lung, kidney, alimentary tract, head and neck etc. ${ }^{2}$ Thyroid secondaries originating from gastrointestinal tract is quite an unusual thing. ${ }^{3}$ Such metastatic lesions on the clinical basis have a very indolent pattern of growth where indications of illness are not so visible thereby creating a disparity in the differential diagnosis with primary carcinoma of thyroid. ${ }^{3}$ Primary squamous cell carcinoma of thyroid has an incidence of $0.2-1.1 \%$ amongst all the thyroidal malignancies stating it to be the rarest entity of all. ${ }^{4}$ In this case report, we are reporting the secondaries to the thyroid from squamous cell carcinoma of larynx $x^{4}$

\section{PRESENTATION OF CASE}

A 54-year-old male presented with complaints of swelling in the anterior part of the neck mimicking as a thyroid swelling which as per the patient is slowly progressive in nature. Change in voice of the patient was also noticed. The swelling was approximately $6 \times 4 \mathrm{~cm}$ which was firm in consistency and moved with deglutition. Other tests like thyroid hormone profile was done which was within normal limits. Fine needle aspiration cytology of clinically palpable thyroid swellings was carried out by standard methods. Aspirates of FNAC were processed and stained conventionally. The stains of Pap and Giemsa were carried out. The cytomorphology was reported by standard available references and texts. Fine-needle aspiration (FNA) of the thyroid swelling was done using the palpation method by the cytopathologist with a 22 -gauge, 4.5 -cm long needle without using the handle. Two passes from different sites were taken.

\author{
Corresponding Author: \\ Dr. Anil Agrawal, \\ Professor, Bachalor Road, \\ Shashtri Chok, Wardha, \\ Maharashtra, India. \\ E-mail: dranilagrawal.456@gmail.com
}

DOI: 10.14260/jemds/2021/34

How to Cite This Article:

Agrawal A, Kedia A, Manchanda A, et al. Primary swellings of thyroid with the cytodiagnosis of invasive squamous cell cancer-a case report. J Evolution Med Dent Sci 2021;10(03):161-163, DOI: 10.14260/jemds/2021/34

Submission 11-09-2020,

Peer Review 16-11-2020,

Acceptance 23-11-2020,

Published 18-01-2021.

Copyright (C) 2021 Anil Agrawal et al. This is an open access article distributed under Creative Commons Attribution License [Attribution 4.0 International (CC BY 4.0)] 
Direct smears were air-dried for May-Grünwald Giemsa staining. Hematoxylin and eosin and Papanicolaou (Pap) staining was done on the smears wet fixed in $95 \%$ alcohol. Cell block was also made. The smears showed sheets, clusters, and scattered malignant squamous cells with moderate anaplasia, hyperchromatic nuclei and scanty dense cytoplasm. Benign follicular epithelial cells, macrophages and bare nuclei were also seen. The tumour cells showed orangeophilia on Pap stain. Cell block preparation showed squamous cell carcinoma (SCC). Cytologic diagnosis of SCC was rendered likely metastatic.

The present case was diagnosed as invasion by squamous cell carcinoma to the thyroid as secondaries. The patient had metastatic squamous cell carcinoma to the thyroid where primary was in larynx. The laryngeal tumour cells directly invaded the thyroid that led to the deposition of metastatic squamous cells in it. The consistent cytomorphological feature was presence of dual cell population of malignant squamous cells and normal or hyperplastic follicular cells in sheets (Figure 2) and blood mixed colloid (Figure 3).
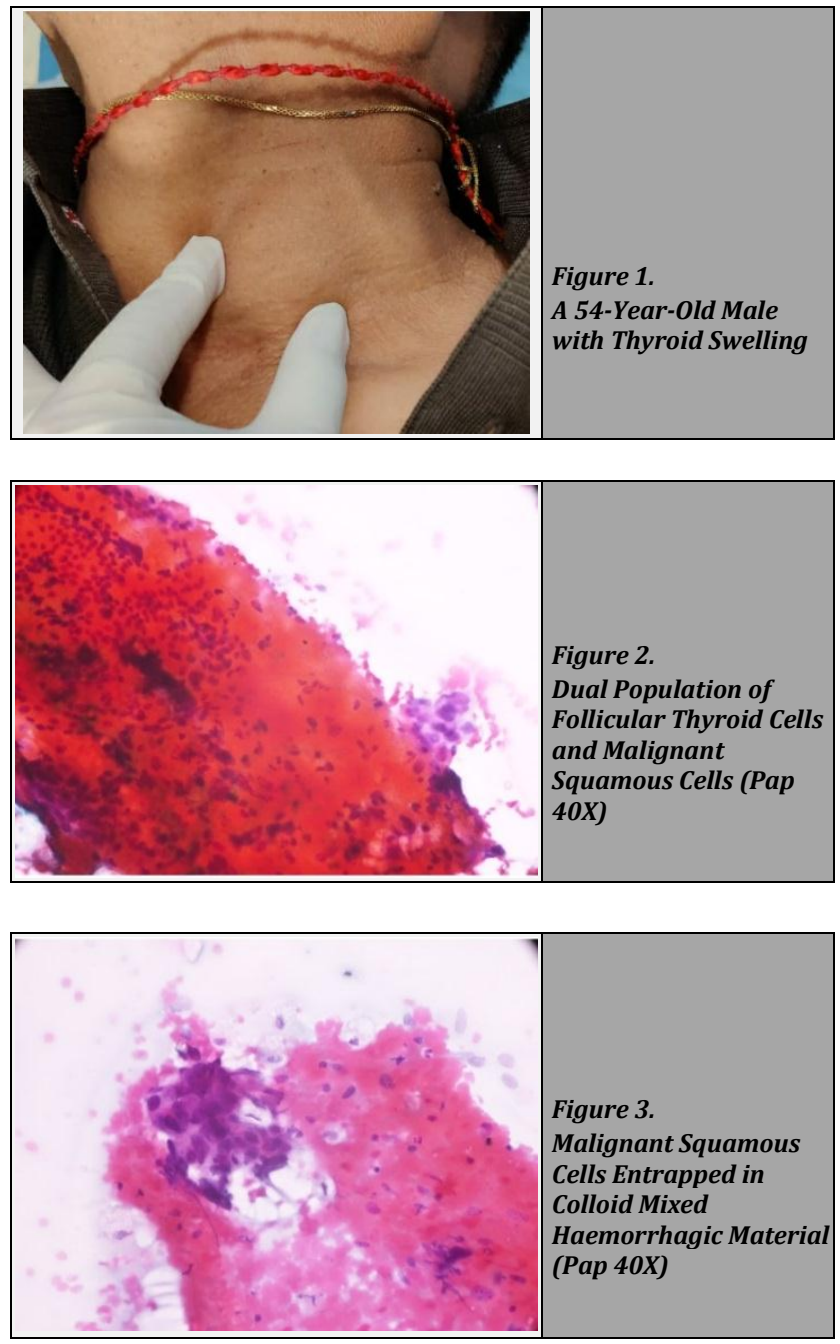

The squamous cells were identified by complete or partial keratinization of cytoplasm which was more prominently appreciated on Pap-stained smears. Squamous cell nuclei possess the characters of hyperchromasia, pleomorphism and spindling. Squamous cell debris in Giemsa appeared blue but were different from blue, magenta flex of colloid. The post FNA biopsy were available from the sites and was reported as well differentiated squamous cell carcinoma. These cytomorphological observations prompt cytopathologist, metastatic or invasive involvement of thyroid by squamous cell carcinoma.

\section{DISCUSSION OF MANAGEMENT}

The metastatic lesions to the thyroid mimics a primary thyroid swelling as quoted on clinical examination. Present study also encountered the similar situation. The metaplastic squamous epithelial cells can be seen in a few benign cystic conditions of thyroid. However, these squamous cells are benign for their nuclear character. ${ }^{1}$ The thyroid is a rare gland for metastasis, however, there are reports in literature where metastatic squamous cell carcinoma in thyroid has been reported.2-5 There are reports of unusual presentation of squamous cell carcinoma being diagnostic on FNAC as metastasis to thyroid originating in uterine cervix ${ }^{2}$ and esophagus. ${ }^{5}$ The commonest cytomorphological feature described for the diagnosis of squamous cell carcinoma metastasis to thyroid is definite by presence of malignant squamous cells, along with thyroid follicular cells.,5 The present study observed that these definite characteristics have been quoted by other authors. $6,7,8$

Squamous cell carcinoma of other locations shows the typical characteristics like autofluorescence ${ }^{9}$ and specified immunohistochemical profiles ${ }^{10}$. Hematogenous spread of cancers from other regions can be suspected to neck region. ${ }^{11-}$ 12 Ghavat et al. reported malignant transformation of solitary cylindroma involving the frontonasal region. ${ }^{13}$ Few studies have reported on different therapeutic aspects of cancer. ${ }^{14,15}$ Due to property of direct tumoural extension, laryngeal cancer presents as a thyroidal mass. ${ }^{2}$ Metastatic deposits to thyroid holds about $2-3 \%$ amongst thyroid neoplasms. ${ }^{3}$ However, diagnosis of secondaries on FNAC holds about $0.1 \%$ of all thyroid masses. ${ }^{3}$ There are three pathways from where secondaries can come to thyroid from various primary sites these are hematogenous, lymphatics or extension of tumour cells directly. ${ }^{3}$ Such low incidence of metastatic thyroidal deposits can be due to its excessive thyroidal blood flow which decreases the deposition of metaplastic squamous cells, excessive iodine in the gland and highly oxygenated milieu of thyroid thus, preventing the abnormal cellular growth. ${ }^{4}$ The diagnosis by FNAC clearly shows presence of metaplastic squamous cells and follicular epithelial cells of thyroid giving it a precise cytomorphological diagnosis. Discrimination between SCC thyroid and thyroidal squamous metaplasia can be done by p53, p21, Molecular Immunology Borstel 1 (MIB-1) markers. The diagnosis of squamous mets was done on FNAC after which clinician was advised to look for the primary site which later was diagnosed as a primary SCC of Larynx. ${ }^{4}$

\section{CONCLUSIONS}

Metastatic lesions to the thyroid masquerades like primary thyroid swelling on clinical examination. Metastatic lesions to the thyroids are either because of direct invasion or from primaries present in oropharyngolaryngeal area or from oesophagus. Lastly, the dual population of malignant squamous cells and normal resident thyroid follicular cells are 
mainstay cytomorphological feature on aspirates of FNAC in diagnostic conclusion of metastatic disease of squamous cell carcinoma to thyroid. Though the primaries can be from varied sites, this case reports a case of SCC of larynx as the primary tumour with its metastasis to the thyroid.

Financial or other competing interests: None.

Disclosure forms provided by the authors are available with the full text of this article at jemds.com.

\section{REFERENCES}

[1] Gooptu S, Sharma S, Singh G, et al. Uncommon metastasis to thyroid gland presenting as a thyroid nodule. International Journal of Case Reports and Images 2013;4(11):615.

[2] Khandelia B, Chakraborti S, Rai S, et al. Metastatic lesions to thyroid associated with dual primaries: a report of two cases. Thyroid Research and Practice 2013;10(3):111-3.

[3] Chen E, Cheng P, Yan X, et al. Metastasis of distal esophageal carcinoma to the thyroid with presentation simulating primary thyroid carcinoma: a case report and review of the literature. World J Surg Oncol 2014;12(1):106.

[4] Kundu R, Punia R, Mohan H, et al. Fine-needle aspiration cytology of metastatic squamous cell carcinoma thyroid: a rare entity. J Cytol 2014;31(4):210-2.

[5] Moulick A. Squamous cell carcinoma of proximal esophagus with simultaneous metastases to thyroid and sternum: a case report and review of the literature. Tanaffos 2012;11(1):67-70.

[6] Dixit A, Khatib MN, Bawankule S, et al. Assessment of serum lipid profile in patients with thyroid disorders in a rural backdrop of central India. Medical Science 2020;24(101):1-11.
[7] Balwani MR, Pasari A, Meshram A, et al. An initial evaluation of hypokalemia turned out distal renal tubular acidosis secondary to parathyroid adenoma. Saudi J Kidney Dis Transpl 2018;29(5):1216-9.

[8] Agarwal A, Bhola N, Kambala R, et al. Touch imprint cytology: can it serve as an alternative to frozen section in intraoperative assessment of cervical metastasis in oral squamous cell carcinoma? J Oral Maxillofac Surg 2019;77(5):994-9.

[9] Bagri-Manjrekar K, Chaudhary M, Sridharan G, et al. In vivo autofluorescence of oral squamous cell carcinoma correlated to cell proliferation rate. J Cancer Res Ther 2018;14(3):553-8.

[10] Milind JM, Shukla S, Acharya S, et al. Utility of histochemical and immunohistochemical profile in grading of squamous cell carcinoma of the oral cavity. Journal of Clinical and Diagnostic Research 2020;14(1):EC1-5.

[11] Panchbhai A, Bhowate R. MRI evaluation of involvement of parotid and submandibular glands by tongue squamous cell carcinoma. Oral Oncol 2020;102:104557.

[12] Gupte M, Jadhav U, Ghewade B, et al. To study the incidence of lung cancer in patients of newly and previously diagnosed chronic obstructive pulmonary disease at AVBRH. Medical Science 2020;24(102):658-63.

[13] Ghavat C, Bhola N, Jadhav A, et al. Malignant transformation of solitary cylindroma involving the frontonasal region- a rarity. Journal of Clinical and Diagnostic Research 2020;14(4):ZD1-4.

[14] Mathur A, Rastogi N, Gurjar D, et al. Safety and efficacy of weekly versus three-weekly paclitaxel plus platinum neoadjuvant chemotherapy in patients with locally advanced squamous cell head and neck carcinoma: a pilot study. South Asian J Cancer 2018;7(4):254-7.

[15] Khatib MN, Gaidhane A, Gaidhane S, et al. Ghrelin as a promising therapeutic option for cancer cachexia. Cell Physiol Biochem 2018;48(5):2172-88. 